\title{
ENTRE A BATUTA E O TUBO DE ENSAIO: A CARREIRA ADMIRÁVEL DE ALEXANDRE BORODIN
}

\section{Carlos A. L. Filgueiras}

Departamento de Química Inorgânica, Instituto de Química, Universidade Federal do Rio de Janeiro, CP 68563, 21945-970 Rio de Janeiro - RJ

Recebido em 20/12/01; aceito em 8/5/02

\begin{abstract}
BETWEEN BATON AND TEST TUBE: THE ADMIRABLE CAREER OF ALEXANDER BORODIN. Alexander Borodin (18331887 ) is a singularity in the history of science. Whereas other scientists may have kept lifelong interests in some artistic field, he was unique in pursuing with great success two parallel careers in both chemistry and music, managing to excell in both to the end of his life. Although he considered himself primarily a chemist, present-day appreciation of his powerful music has greatly surpassed interest for his chemistry. This article treats the life and the unusual double career of the Russian chemist-musician.
\end{abstract}

Keywords: Borodin; chemistry and music; science and art.

Alexandre Borodin foi um indivíduo extraordinário que seguiu dois chamamentos absolutamente diferentes, vindo a trilhar com grande desenvoltura e reconhecimento carreiras distintas na ciência e na arte. A singularidade de sua pessoa e as atividades que exerceu merecem um estudo, sobretudo no mundo do século 21 , quando o divórcio entre a ciência e a cultura humanística e artística é tido por muitos como inevitável, embora deplorável.

Antes de Borodin, o alemão Wilhelm Herschel (1738-1822) iniciou sua vida como músico, tocando oboé com a Guarda de Hanover desde os 14 anos. Cinco anos depois estava na Inglaterra, onde mudou o prenome para William. Sua carreira artística continuou, até ser nomeado organista na cidade de Bath. Ao mesmo tempo, foi crescendo nele um interesse pela astronomia, que acabou suplantando a música. A carreira musical foi abandonada completamente, e Herschel tornou-se um cientista importante, tendo descoberto com o telescópio um grande número de corpos celestes. Suas descobertas mais famosas foram o planeta Urano, em 1781, e a radiação infravermelha ${ }^{1}$.

Em época mais próxima a nós houve também o caso do americano Lejaren Hiller Jr. (1924-1994) ${ }^{2}$. Hiller sempre demonstrou um pendor tanto para a ciência como para a música. Em 1947, ele defendeu uma tese de doutorado em química na Universidade de Princeton a respeito da estrutura da celulose e do amido, seguindo-se uma carreira como químico industrial na Companhia Du Pont e como químico acadêmico na Universidade de Illinois. Ao mesmo tempo prosseguiu sua carreira paralela como músico, compondo e executando um grande número de peças, em muitos casos no novo campo da música eletro-acústica, com extenso uso de computadores. Data de 1962 sua última publicação científica. Em 1958, porém, ele já estava no Departamento de Música da Universidade de Illinois, de onde se transferiu, em 1968, para uma cátedra especial de música na Universidade de Nova York em Buffalo, onde permaneceu até o fim de sua carreira, tendo ganhado fama como músico de vanguarda. É digno de menção que ele passou um período lecionando música em Salvador, na Bahia, em 1980. Daí surgiu uma composição sua, intitulada "Uma Apoteose de Arqueoptérix", escrita para berimbau.

Hiller é o oposto de Herschel, passando de cientista profissional a uma carreira cxclusivamente como músico, embora num processo de transição bem mais lenta. Em Hiller a música acabou sobrepujando a química, totalmente.

*e-mail: calf@iq.ufrj.br
Borodin é um caso totalmente à parte na história da ciência. A devoção tanto à química como à música foram uma constante, tornando-se o único praticante de uma carreira dupla dessa natureza ao longo de toda a vida. Ao contrário de Herschel, Borodin se rebelaria contra a sentença dada pelos versos do poeta inglês Alexander Pope ${ }^{1}$ :

"One science only will one genius fit;

So vast is art, so narrow human wit."

Contudo, a importância de Borodin na história da música, por sua originalidade e pioneirismo, é de tal monta que hoje poucos conhecem seu papel como pesquisador e professor de química na Rússia do século 19. Sua trajetória como químico, mesmo sem que tivesse tido uma carreira tão distinguida na música, merece também ser analisada.

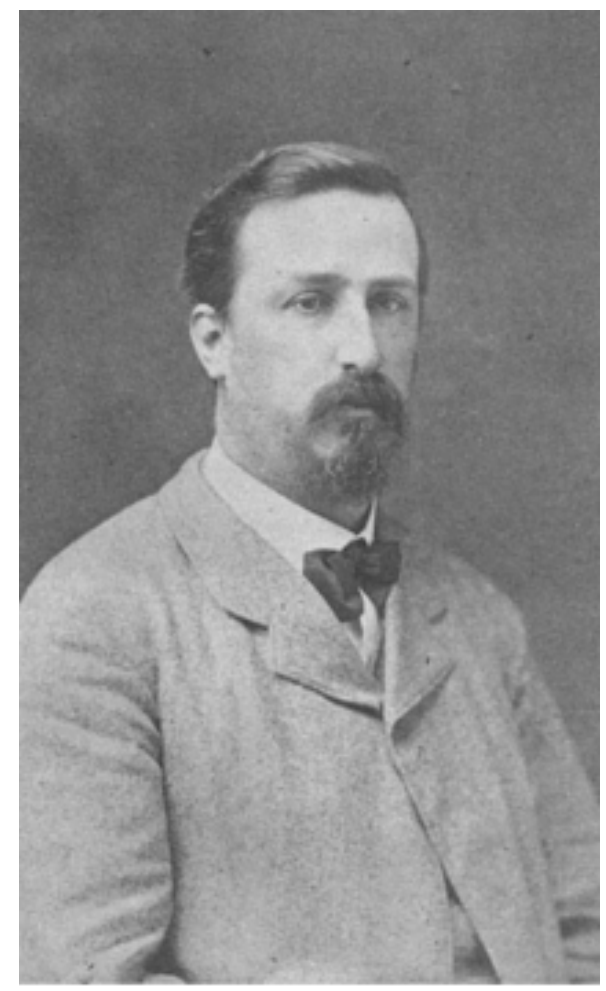

Figura 1. Retrato de Borodin em 1873 
Após algumas publicações esporádicas encontradas na literatura ocidental mais antiga ${ }^{1,3,4}$, apareceram vários artigos à época do centenário de morte de Borodin, em 1987 ${ }^{5-7}$. Em 1988 foi publicada a tradução em inglês de um importante livro russo sobre ele ${ }^{8}$. No entanto, ainda não existe em português qualquer trabalho a respeito desta figura tão singular.

Aleksandr Porfirievich Borodin, ou Alexandre Borodin, nasceu em São Petersburgo, então capital do Império Russo, em 12 novembro de 1833. Pelo calendário juliano, usado na Rússia até 01 de fevereiro de 1918, a data era 31 de outubro, ou seja, com uma defasagem de 12 dias. Ele era filho natural do príncipe Luka Stepanovich Gedianov (1772-1840), descendente dos antigos reis da Imeretia, ao sul do Cáucaso. Como o resto da Geórgia, a região havia sido anexada pela Rússia em 1810. A mãe do jovem Alexandre era Avdotia Konstantinova Antonova (1809-1873), que veio a casar-se em 1839 com o médico militar Khristian Ivanovich Kleineke. Alexandre foi acostumado a chamar sua mãe de "titia", e assim procedeu toda a vida. Para salvar as aparências, o menino foi registrado como filho de um servo do Príncipe Gedianov, Porfirii Ionovich Borodin, e de sua mulher Tatiana Grigorievna Borodina.

Desde cedo o jovem Sacha (alcunha russa para Alexandre) demonstrou um invulgar talento musical. Por isso, aos 8 anos a mãe arranjou para que tomasse aulas de flauta com um músico da orquestra de um regimento militar. Aos 9 anos Sacha compôs sua primeira peça, uma polca intitulada Hélène, dedicada a uma menina por quem se apaixonara, Elena. Ele também se destacou nos estudos, dominando várias línguas, como o alemão, o francês e o inglês. Mais tarde viria também a aprender italiano.

Uma grande amizade se formou entre Alexandre e seu colega de estudos Mikhail (Micha) Schchiglev, que viria a tornar-se professor de música e compositor. Aos 12 anos de idade, Sasha decidiu aprender a tocar violoncelo, enquanto Micha se dedicava ao violino, ambos como autodidatas. $\mathrm{O}$ objetivo dos dois era desenvolver a familiaridade com a música de câmara. Eles também tiveram aulas de piano com um professor de música, que não os satisfez. Para compensar, decidiram tocar juntos arranjos para 4 mãos de todas as sinfonias de Beethoven, Haydn e Mendelssohn. Além dos instrumentos já mencionados, Borodin também tocava oboé, clarineta e vários metais?.

Em 1847, aos 14 anos, Borodin compôs um concerto para flauta e piano, que foi executado por ele e seu companheiro Schchiglev. No mesmo ano também escreveu um trio para dois violinos e violoncelo sobre um tema de Meyerbeer, "Robert le Diable". Estas composições iniciais, assim como outras obras da juventude, lamentavelmente se perderam ${ }^{10}$.

Pouco depois de despertar para a música o jovem Sacha tomou contato com as ciências, que o fascinaram. Os preceptores que teve em casa muito influenciaram o enorme prazer que a química, sobretudo, lhe proporcionava. Seu amigo de adolescência, Schchiglev, escreveu a esse respeito: "o apartamento estava quase inteiramente repleto de frascos, retortas e todo tipo de reagentes. Em toda parte as janelas tinham tubos com várias soluções cristalinas (sic)"10

Em 1850, aos 17 anos, uma nova vida iria começar para o jovem Sacha Borodin. Nessa data ele foi admitido como estudante da Academia Médico-Cirúrgica de São Petersburgo. A instituição havia sido fundada em 1798, e já possuía renome. Ele foi aluno de um grande químico russo, o Prof. Nikolai Nikolaievich Zinin (1812-1880), que tinha vindo da Universidade de Kazan, em 1847, precedido da fama conquistada com a descoberta da redução de compostos nitroaromáticos para as aminas correspondentes, reação de grande importância para a nascente produção de corantes sintéticos. Borodin escreveria a respeito de seu professor: "Suas palavras da cátedra não eram apenas uma reprodução confiável das condições contemporâneas, mas também uma tribuna das novas tendências na ciên- cia. Ele não era econômico em idéias; dispersava-as a torto e a direito, e repetidas vezes desenvolvia temas em suas aulas que só seriam ouvidos muitos anos depois, como uma nova descoberta ou uma nova idéia científica" ${ }^{\text {. }}$.

As condições de trabalho experimental na Academia eram, todavia, deploráveis, despertando no aluno mais admiração pelo professor Zinin. Borodin era um aluno dedicado e incansável. Seu ardor pelo estudo de anatomia, porém, quase lhe custou a vida, pois veio a contrair uma infecção de um cadáver, de que só a custo conseguiu se curar. Sua paixão maior era, contudo, a química, o que levou Zinin a declarar publicamente que tinha a esperança de ser sucedido por seu brilhante aluno. No entanto, Zinin também se preocupava com o que para ele era uma obsessão de Borodin, que sempre que podia se punha a tocar piano ou a freqüentar concertos e óperas. A este respeito disse-lhe o mestre: "Senhor Borodin, preocupe-se um pouco menos com canções. Estou pondo todas as minhas esperanças no senhor como meu sucessor, e o senhor só pensa em música; não dá para caçar duas lebres ao mesmo tempo" 12 .

Borodin tinha uma verdadeira veneração por Zinin, e retrucava que a música para ele nada mais era que uma distração.

Após ser aprovado nos exames finais de 1856, o jovem médico graduou-se em primeiro lugar em sua turma. Mesmo antes da formatura, ele já havia sido indicado para professor da Academia MédicoCirúrgica. A profissão de médico não o atraía, já que não podia ver sangue sem desmaiar. Seu verdadeiro amor era a química, e foi ela que ele escolheu para sua tese de doutorado. Esta veio a ser defendida em 1858, e se intitulou "Da Analogia do Ácido Arsênico com o Ácido Fosfórico no Comportamento Químico e Toxicológico". Sua tese o mostra bem atualizado na química, ao defender as novas teorias unitárias dos químicos franceses Auguste Laurent e Charles Gerhardt, em contraposição à teoria dualística de Berzelius.

Durante seu doutorado, Borodin veio a conhecer um jovem oficial do exército, de apenas 17 anos, que se tornará um grande amigo e um nome de primeira grandeza na música russa: Modest Petrovich Mussorgsky (1839-1881). Também nesse período ele foi ao estrangeiro pela primeira vez. Em 1857, foi designado pela Academia para participar do Congresso Internacional de Oftalmologistas em Bruxelas. Ao passar por Paris, sua esperança de encontrar Berthelot se frustrou, pois o químico francês não se encontrava na cidade ${ }^{13}$.

Em 1858 saíram suas primeiras publicações científicas, a respeito da química da hidrobenzamida e da amarina ${ }^{14,15}$. A hidrobenzamida pode ser obtida condensando-se o benzaldeído e a amônia, e a amarina se obtém da hidrobenzamida por aquecimento ou por tratamento daquele composto com uma base. Suas fórmulas estruturais são dadas abaixo.<smiles>C(=NC(N=Cc1ccccc1)c1ccccc1)c1ccccc1</smiles>

Hidrobenzamida

Amarina

Este rearranjo é um tópico difícil de química orgânica, que atraiu as atenções de muitos químicos por largos anos, até nossos dias ${ }^{16}$.

Borodin reagiu cada um dos compostos acima com iodeto de etila, na proporção molar de 1:2, para converter os grupos $\mathrm{NH}$ em NEt e determinar o número de terminações NH de cada substância, tendo chegado à conclusão de que esse número era zero e um, respectivamente, nos dois compostos estudados ${ }^{14}$.

$\mathrm{Na}$ etapa seguinte ele usou o mesmo método para investigar a benzanilida. A reação se passa com a etilação ocorrendo no oxigênio, e não no nitrogênio, como ele acreditava. Assim, acabou obten- 
do um resultado certo, o gasto de apenas um mol de iodeto de etila por mol de benzanilida, mas por razões erradas ${ }^{15}$ :

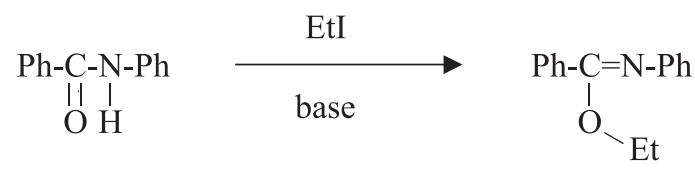

Benzanilida

Anos depois ele retornou a esse estudo, apresentando-o num congresso em Kazan, em 1873. Desta feita, Borodin reagiu o cuminaldeído, $\left(\mathrm{CH}_{3}\right)_{2} \mathrm{CHC}_{6} \mathrm{H}_{4} \mathrm{CHO}$, com amônia, obtendo uma hidramida que se rearranja por aquecimento, dando um análogo da amarina ${ }^{17}$. Dois anos depois aparece um trabalho descrevendo a reação do ácido nitroso com a amarina, em etanol, gerando a nitrosoamarina ${ }^{18}$. Esta reação demonstrou que a amarina é uma amina secundária, já que o produto é um nitrosoderivado, e não um composto de diazônio. Como a reação apresenta uma razão 1:1 dos reagentes, a amarina deve ter apenas um grupo $\mathrm{NH}$.

Em 1859 saíram duas publicações locais, em russo, a respeito da análise química das águas minerais de Soligalich. Este estudo veio a resultar na construção de um hospital no local. O relatório de Borodin foi publicado tanto num jornal de Moscou como em forma de folheto ${ }^{19}$.

A partir dessa época Borodin deixou de vez a medicina, concentrando-se em sua atividade como pesquisador e professor de química na Academia Médico-Cirúrgica.

Em 1859 a Academia decidiu enviar o jovem professor para um estágio de dois anos no estrangeiro, que foi depois ampliado por mais um ano. Ao final daquele ano, Borodin chegou a Heidelberg, então um grande centro de pesquisa química e física. Nessa época, os professores Robert Bunsen (1811-1899) e Gustav Robert Kirchhoff (1824-1887) estavam trabalhando num novo projeto, a espectroscopia atômica, que veio a tornar-se um fator de importância no progresso tanto da química como da física no século $19^{20}$. Uma das aplicações da espectroscopia foi a descoberta, desde aquele mesmo ano, de vários elementos novos. Em Heidelberg também trabalhavam na época os químicos orgânicos Friedrich August Kekulé (1829-1896), Johann Friedrich Adolf von Baeyer (1835-1917) e Richard August Carl Emil Erlenmeyer (1825-1907). O ex-aluno de Bunsen, Henry Enfield Roscoe (1833-1915), recentemente nomeado professor no Owens College de Manchester, vinha regularmente passar os verões com seu antigo orientador, no desenvolvimento de novas pesquisas. Entre outros químicos famosos que estudaram em Heidelberg, podem ser citados, sem esgotar a lista, Lothar Meyer (1830-1895) e Friedrich Konrad Beilstein (1838-1906) ${ }^{1}$. Havia uma numerosa colônia estudantil russa na cidade, e Borodin associou-se prontamente a ela. Dois outros jovens químicos russos, de fama futura, que lá estavam nessa época eram Alexandre Mikhailovich Butlerov (1828-1886) e Dmitri Ivanovich Mendeleev (1834-1907). Borodin, que já tinha um doutorado, tinha certa liberdade com relação à pesquisa que quisesse fazer. Ele trabalhou no laboratório de Erlenmeyer, mas independentemente. Sua pesquisa consistia em sintetizar derivados da benzidina (ou 4,4'-diaminobifenila) e outras aminas aromáticas relacionadas, a fim de estudar o difícil problema do rearranjo que leva do hidrazobenzeno ao cloridrato de benzidina, segundo a equação esquemática dada a seguir:

$$
\mathrm{C}_{6} \mathrm{H}_{5} \mathrm{NH} . \mathrm{HNC}_{6} \mathrm{H}_{5}+2 \mathrm{HCl} \rightarrow\left[\mathrm{H}_{3} \mathrm{NC}_{6} \mathrm{H}_{4} \cdot \mathrm{C}_{6} \mathrm{H}_{4} \mathrm{NH}_{3}\right]^{2+}+2 \mathrm{Cl}^{-}
$$

O interesse nesse tipo de reação era muito grande, por causa da nascente indústria de corantes orgânicos que não necessitassem de um mordente para serem fixados aos tecidos.
O que Borodin fez, embora de forma muito incipiente, foi estudar o chamado rearranjo da benzidina, que é uma reação geral para N,N'-diaril-hidrazinas, as quais, por tratamento com ácido, originam vários produtos, como a benzidina e a semidina (2,4'diaminobifenila), além de outros isômeros ${ }^{21}$. Este rearranjo tem sido muito estudado até nossos dias, e dele existem muitas publicações na literatura química corrente ${ }^{22}$.

Zinin havia preparado a benzidina e determinado seu caráter dibásico em 1845, ao trabalhar com o azobenzeno ${ }^{23}$. Hofmann, em 1860 , estabeleceu que a reação passava pelo hidrazobenzeno ${ }^{24}$, e Fittig, em 1862, mostrou que ela podia ser preparada por uma bisnitração da bifenila, seguida de uma redução com sulfeto de amônio, confirmando também sua natureza dibásica ${ }^{25}$. Embora Fittig dê crédito a Hofmann, não menciona Borodin.

Mendeleev havia ido a Heidelberg com a intenção de trabalhar no laboratório de Bunsen, mas percebeu que o professor alemão estava agora completamente entretido com seus estudos de espectroscopia, e pouco interessado na química orgânica, como no passado. Por isso decidiu montar um laboratório em casa, onde passou a determinar constantes físicas ${ }^{26}$, que depois lhe foram úteis ao descrever as propriedades dos elementos, tanto conhecidos como por descobrir, em sua famosa Classificação Periódica, que surgiria em 1869.

Durante o inverno de 1859-60, Borodin fez uma viagem curta a Paris, com a finalidade de comprar itens de laboratório que ele não conseguia obter na Alemanha. Durante os nove dias passados na capital francesa, teve a oportunidade de visitar Berthelot e seu laboratório, e em seu relatório ao Diretor da Academia, em São Petersburgo, escrito em fevereiro de 1860, descreve como o químico francês foi atencioso e solícito com ele. Ao mesmo tempo queixa-se dos gastos que teve com a compra de materiais de laboratório, que foram custeados com sua bolsa de estudos ${ }^{27}$.

Os químicos russos em Heidelberg se reuniam freqüentemente, e de suas discussões surgiu o embrião da futura Sociedade Química Russa, que viria a ser fundada anos mais tarde.

A música, que não era na época a maior preocupação de Borodin, não foi esquecida, todavia. Ele tocava regularmente em conjuntos de cordas, e na primavera de 1860 compôs um sexteto para dois violinos, duas violas e dois violoncelos, que teve sua primeira execução em Heidelberg ${ }^{28}$.

No verão de 1860, seu ex-professor, Zinin, que viajava pela Europa Ocidental, chegou a Heidelberg. De lá, ele, Borodin e Mendeleev fizeram uma viagem à Itália, após a qual regressaram à Alemanha para participar de um acontecimento de grande importância: o Congresso de Karlsruhe, o primeiro congresso científico internacional, que teve lugar naquela cidade alemã de 3 a 6 de setembro daquele ano $^{29}$. Os maiores químicos do mundo estavam presentes em Karlsruhe, e esta foi uma oportunidade fantástica para o jovem químico Borodin inteirar-se, em primeira mão, dos grandes debates científicos da época. Entre estes, havia um desconforto crescente em virtude da autoridade de Jöns Jakob Berzelius (1779-1848), cuja teoria dualística havia dominado a química, mas mostrava-se agora um empecilho ao progresso da química orgânica. Para Berzelius, os compostos eram formados por uma parte eletropositiva e outra eletronegativa, e a ligação química resultava de uma atração de natureza eletrostática. Isso poderia funcionar para um grande número de compostos inorgânicos, desde que eles fossem o que nós hoje denominamos compostos iônicos. Todavia, para a química orgânica, que era o ramo que mais crescia na química, a teoria dualística falhava redondamente. Como explicar que um hidrogênio, que era considerado eletropositivo, como nos ácidos, pudesse ser substituído no benzeno por um cloro, de natureza eletronegativa, dando o clorobenzeno? A teoria unitária dos químicos franceses Auguste Laurent (1808-1853) e Charles Frédéric Gerhardt (1816-1856), de- 
senvolvendo idéias de Jean Baptiste Dumas (1800-1884), havia descartado as idéias de Berzelius e proposto um esquema geral em que as reações se dão por substituição de átomos ou grupos inteiros de átomos, os radicais. Além dessa dificuldade de explicar compostos tão diferentes em suas propriedades como os sais inorgânicos e os compostos aromáticos, havia também o problema da determinação dos pesos atômicos, que se encontrava numa situação de verdadeiro caos, com pesos e fórmulas diferentes para um mesmo composto, dependendo do autor. Não havia uma distinção precisa, como temos hoje, entre os conceitos de átomo e molécula, por isso os químicos preferiam trabalhar com o hoje obsoleto conceito de equivalente.

O maior mérito do Congresso de Karlsruhe deveu-se a uma iniciativa do químico italiano Stanislao Cannizzaro (1826-1910). Cannizzaro havia publicado em 1858 um livro para servir de texto a seu curso de química na Universidade de Gênova. Nesse livro ele havia utilizado com vantagem a esquecida hipótese de Avogadro, que jazia ignorada pela maioria dos químicos havia décadas. Pela hipótese, hoje chamada Princípio de Avogadro, ficava muito clara a distinção entre átomos e moléculas, e muitos dos problemas da química da época simplesmente se desvaneciam. Ao final do congresso, Angelo Pavesi, amigo de Cannizzaro e professor de química na Universidade de Pavia, distribuiu cópias do trabalho de seu compatriota. Esta publicação impressionaria bastante o químico alemão Lothar Meyer, que, ao escrever seu influente livro As Teorias Modernas da Química e seu Significado para a Estática Química, saído à luz em 1864, incorporaria as idéias de Cannizzaro e de Avogadro, resolvendo de vez as querelas intermináveis em torno dos conceitos de átomo e molécula.

De Karlsruhe, Zinin regressou à Rússia e Borodin e Mendeleev à Itália. Na primeira viagem eles haviam visitado Veneza, Verona e Milão; desta vez foram a Gênova e Roma, após o quê Borodin se dirigiu mais uma vez a Paris, onde passou vários meses aprendendo polarimetria e freqüentando os cursos do físico-químico Victor Regnault (1810-1878) e do fisiologista Claude Bernard (1813-1878). Em seu minucioso relatório enviado à Academia $^{30}$, Borodin diz que o curso de Regnault, intitulado Sobre o Calórico, "era sério e dirigido para pessoas que já conhecem física e matemática elementares, $e$ foi extremamente interessante. As aulas desse cientista não eram apenas demonstrativas, mas também filosóficas. Elas eram particularmente notáveis na profundidade e totalidade da opinião crítica, na riqueza de idéias independentes e novas, e na clareza da apresentação. Pode-se compreender tudo isso se se lembra que a maior parte desse ramo da física foi criada pelos trabalhos do próprio Regnault."

Quanto a Bernard, seu curso, "menos especial e dirigido principalmente para médicos, foi notável na riqueza de novos fatos e clareza e simplicidade incomuns de apresentação. Claude Bernard possui a rara habilidade de transmitir a ciência de tal maneira que cada aula fica gravada na memória do ouvinte sem qualquer esforço da parte deste."

Borodin também freqüentou as aulas de Henri Hureau de Sénarmont (1808-1862), na Escola Politécnica, a respeito de condutividade térmica e elétrica, e índices ópticos de cristais. Outros laboratórios foram também visitados, como os de Sainte-Claire Deville e de Pasteur na Escola Normal Superior. Frequientemente ia também a conferências no Collège de France, na Escola de Medicina, na Escola de Farmácia, na Sorbonne, na Escola Normal, no Jardim das Plantas, no Conservatório de Artes e Ofícios, “com o único objetivo", conforme escreveu, "de me familiarizar com a maneira de ensinar dos professores franceses, pois em nenhum outro lugar são dadas aulas com tal clareza e elegância como na França."

Borodin, que já era membro da Sociedade Química Francesa, freqüentou também suas reuniões, onde apresentou seus trabalhos químicos. Nesse período ele começou a se interessar pela ação do bromo sobre os sais de prata de ácidos carboxílicos, tendo publicado em 1861 três artigos sobre o assunto, sendo um deles na França e os outros dois na Alemanha. Em 1860, Borodin usa o método de Péligot para a síntese do ácido bromobenzóico ${ }^{31}$ e prepara os ácidos bromobutírico e bromovalérico ${ }^{32}$. Este trabalho será retomado mais tarde e culminará, em 1869, com a descoberta de um método geral para reduzir em um carbono o comprimento de uma cadeia orgânica. Ao tentar destilar os ácidos bromobutírico e bromovalérico, percebeu que eles se decompunham. No entanto, ao fazer o mesmo procedimento com o ácido bromoacético, acabou obtendo o bromometano, ou seja, o processo, que se mostrou geral, produzia um composto cuja cadeia tinha um carbono a menos que o reagente de partida, de acordo com a equação abaixo:

$\mathrm{RCOOAg}+\mathrm{Br}_{2} \rightarrow \mathrm{RBr}+\mathrm{CO}_{2}+\mathrm{AgBr}$

A reação descoberta por Borodin permaneceu num certo limbo até ser "redescoberta", em 1942 na Alemanha, por Heinz e Cläre Hunsdiecker ${ }^{33}$, e a reação é chamada hoje, pela maioria dos químicos ocidentais, de "reação de Hunsdiecker", numa injustiça flagrante com a prioridade de Borodin, que poucos autores reconhecem ${ }^{34}$.

Na primavera de 1861, Borodin retornou a Heidelberg, onde conheceu uma jovem russa de Moscou, Ekaterina (Katia) Sergeeevna Protopopova, que havia saído do rigor do clima russo por razões de saúde. Katia era uma excelente pianista, e conquistou Borodin com suas interpretações de Chopin, Schumann e Liszt. Os dois tornaramse inseparáveis.

Ainda em Heidelberg Borodin empreendeu uma tentativa frustrada de preparar um homólogo do ácido benzílico pela reação de benzila com amilato de sódio $^{35}$. O produto obtido, todavia, era o próprio ácido benzílico:

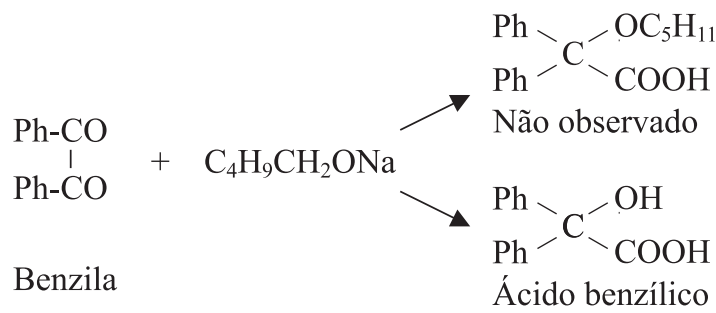

Com a chegada do outono e a aproximação do inverno, ele e Katia decidiram ir à Itália, cujo clima seria mais favorável para os problemas de saúde dela. Os químicos da Universidade de Pisa Sebastiano de Luca (1820-1880) e Paolo Tassinari (1829-1909) convidaram seu colega russo a passar algum tempo em seu laboratório, o que deixou Borodin radiante. Além de gostar muito da Itália, o laboratório posto a sua disposição era excelente, e ainda havia a vantagem de Katia poder sair do inverno alemão ${ }^{36}$.

Em Pisa Borodin trabalhou em vários assuntos, mas o mais importante foi a investigação que levou à preparação de fluoretos orgânicos. A química do flúor estava em sua infância e os únicos fluoretos orgânicos conhecidos eram o fluorometano e o fluoroetano, obtidos, respectivamente, por Dumas e Péligot em $1836^{37}$, e por Frémy em $1856^{38}$.

Borodin supunha que o ácido fluorídrico fosse dibásico, o que concorda com a idéia moderna de que ele seja uma solução contendo $\mathrm{H}^{+}$e $\mathrm{HF}_{2}^{-}$. Para elucidar este aspecto, ele decidiu estudar inicialmente a ação do ácido acético sobre os fluoretos alcalinos:

$\mathrm{CH}_{3} \mathrm{COOH}+2 \mathrm{KF} \rightarrow \mathrm{CH}_{3} \mathrm{COOK}+\mathrm{KHF}_{2}$ 


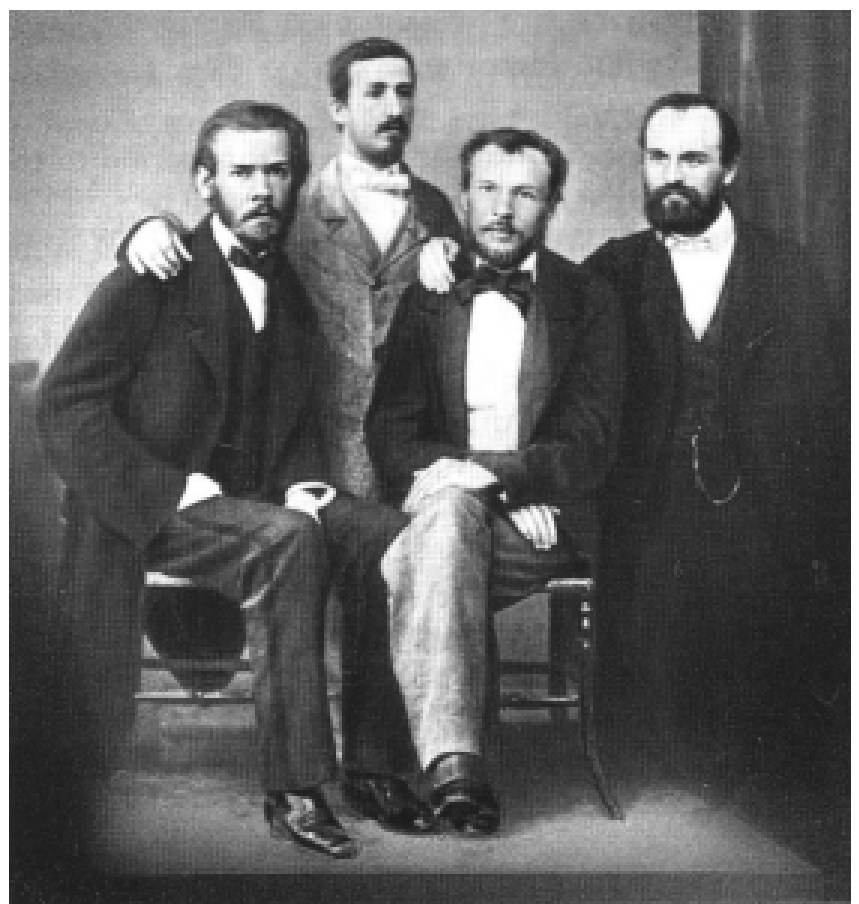

Figura 2. Estudantes russos em Heidelberg: da esquerda para a direita, o segundo é Borodin e o terceiro é Mendeleev

Uma reação análoga se passa com o fluoreto de sódio. Essas reações mostram que os fluoretos alcalinos têm uma tendência tão acentuada para formar hidrogenofluoretos, que devem reagir com ácidos fracos na proporção 1:2, como evidenciado na reação acima. Em seguida ele variou o ácido, efetuando a reação com os ácidos benzóico, valérico, cítrico, oxálico e tartárico, obtendo sempre resultados semelhantes. Além disso, o fluoreto é capaz de substituir o cloreto, como na preparação que ele fez do fluoreto de benzoíla, usando o hidrogenofluoreto ou o fluoreto de potássio ${ }^{39}$ :

$\mathrm{C}_{6} \mathrm{H}_{5} \mathrm{COCl}+\mathrm{KHF}_{2} \rightarrow \mathrm{C}_{6} \mathrm{H}_{5} \mathrm{COF}+\mathrm{HF}+\mathrm{KCl}$

ou $\mathrm{C}_{6} \mathrm{H}_{5} \mathrm{COCl}+\mathrm{KF} \rightarrow \mathrm{C}_{6} \mathrm{H}_{5} \mathrm{COF}+\mathrm{KCl}$

Também nessa área, pouco crédito se deu posteriormente ao trabalho de Borodin.

Katia escreveu a respeito do período passado em Pisa:

"A química não impediu que Alexandre também dedicasse algum tempo à música. Por exemplo, ele tocava violoncelo na orquestra do teatro de Pisa... Em Pisa ficamos conhecendo o diretor da escola de música local, o Signore Menocchi. Ele era um homem amável, mas não um músico excepcional. Lembro-me que uma vez, na sua presença, Alexandre escreveu uma fuga em algumas horas. Você devia ver o espanto do Signore Professore. Daí em diante ele começou a olhar para Alexandre Porfirievich como uma maravilha musical"40.

Em Pisa, Borodin compôs uma tarantela para piano a quatro mãos e um quinteto para cordas e piano. No verão de 1862 ele retornou à Rússia com Katia, após uma ausência de quase três anos. Em outubro do mesmo ano foi nomeado para o cargo temporário de Professor Assistente de Química pela Direção da Academia Médico-Cirúrgica. Em dezembro prestou concurso e foi efetivado no cargo. A partir de 1864 ele substituiria seu ex-professor Zinin nas aulas, pois este último passaria a se ocupar apenas de pesquisa. Numa carta de 1863 a Butlerov ele se queixa amargamente das dificuldades materiais para levar a cabo seu trabalho, assim como da terrível burocracia ${ }^{41}$.
No dia 17 de abril de 1863 Borodin e Katia se casaram em São Petersburgo. No mesmo ano a Direção da Academia lhe concedeu um apartamento em seu novo prédio. Aí ele viveu até seu último dia. O professor da Academia Aleksei Petrovich Dobroslavin (1842-1889) escreveu a respeito de seu colega:

"O laboratório estava situado no corredor do apartamento, $e$ Borodin trabalhava infatigavelmente com os estudantes todos os dias. No entanto, durante o trabalho Borodin sempre mantinha sua disposição solícita e bem-humorada com alunos e colegas, e estava sempre pronto a interromper qualquer de seus trabalhos sem impaciência, sem irritação, de modo a responder quaisquer perguntas que lhe fizessem. Quem trabalhasse no laboratório sentia-se como se estivesse num círculo familiar. Mas ele não esquecia a música. Durante o trabalho, quase sempre cantarolava alguma coisa consigo mesmo; estava pronto a falar e discutir com os outros sobre novidades musicais, tendências e técnicas de composição musical. Quando estava no apartamento, freqüentemente ouvíamos os sons harmoniosos do piano do professor, que se espalhavam pelo corredor do laboratório. $O$ bomhumor e a atenção de Borodin afetavam a todos. Qualquer um podia ir até ele com suas idéias, perguntas e opiniões; nunca encontrava recusa, arrogância ou desdém. Raramente se conseguia provocar alguma demonstração de irritação em Borodin, e mesmo assim só por falta de cuidado ou atitude negligente em relação ao trabalho da parte das pessoas no laboratório...

A atitude sincera, calorosa de Borodin com os estudantes não estava restrita ao laboratório. Quase todos que trabalhavam lá eram aceitos em sua família como conhecidos dos mais íntimos. Com freqüência tomavam o desjejum, participavam do almoço e até do jantar, quando permaneciam no laboratório por períodos longos. $O$ apartamento de Borodin, deve-se dizer, estava sempre escancarado para todos os jovens. Ele se preocupava constantemente com o destino de cada estudante ao graduar-se na Academia, lançando mão de todos os esforços para ajudá-lo. Dizia-se com freqüência que era impossível encontrá-lo em sociedade sem que ele perguntasse por alguém ou tentasse arranjar alguma coisa para alguém"42.

A velha idéia de fundar uma Sociedade, várias vezes discutida entre os químicos russos em Heidelberg, voltou a ganhar força, com a formação de um grupo em São Petersburgo, que incluía Borodin, e que se reunia uma vez por mês a fim de discutir assuntos de química. A partir daí veio efetivamente a constituir-se a Sociedade Química Russa, criada na Universidade de São Petersburgo em $1868^{43}$.

A música nunca deixou de estar presente na vida de Borodin. No início dos anos sessenta ele se aproximou de outros músicos promissores que estavam sob a forte influência de Mikhail Glinka (18041857) e sua música profundamente ligada às raízes russas. Este grupo veio a ser chamado de "Grupo dos Cinco", ou "Grupinho Poderoso". Seus componentes eram, além de Borodin, Milii Alekseevich Balakirev (1836-1910), Modest Petrovich Mussorgsky (1839-1881), Nikolai Andreevich Rimsky-Korsakov (1844-1908) e Cesar Antonovich Cui (1835-1918). O grupo enfatizava a necessidade de aproximar a música russa de suas raízes eslavas e asiáticas, em contraposição à posição mais internacionalista de outros músicos russos da época, como Piotr Ilich Tchaikovsky (1840-1893), admirador, todavia, da música de Borodin, ou os irmãos Rubinstein, Anton (1829-1894) e Nikolai (1835-1881).

Os anos em que o Grupo dos Cinco esteve unido foram muito profícuos. Basta citar as óperas Boris Godunov, de Mussorgsky, A Jovem de Pskov, também conhecida como Ivan o Terrível, de RimskyKorsakov, e Ratcliff, de Cui. Nessa época sai à luz a Sinfonia Número 1 de Borodin, além de várias canções de grande brilho.

Havia uma certa tendência bastante afetada e estrangeirada em São Petersburgo, que fazia mofa da música do Grupo dos Cinco, o que levou Borodin a escrever: 
"No que me diz respeito, estou desapontado em nossa fraternidade... Cada um faz grande esforço para se tornar francês ou inglês, para bajular ante o julgamento da Europa. Não há a mínima mostra de independência nacional; ao contrário, o que há é uma completa ausência de individualidade" ${ }^{\prime 4}$.

Em 15 de abril de 1864 Borodin foi eleito Professor Titular da Academia. Nos anos 60 ele também começou um dos capítulos mais interessantes de sua vida científica, com seus estudos sobre aldeídos. Em 1864 ele tratou o valeraldeído com sódio na esperança de obter o valerato de sódio $^{45}$. Em notação moderna, a reação dava o intermediário mostrado abaixo, que se associava em produtos de condensação:

$$
\mathrm{C}_{3} \mathrm{H}_{7}-\mathrm{CH}_{2}-\mathrm{CHO}+\mathrm{Na} \rightarrow \mathrm{C}_{3} \mathrm{H}_{7}-\overline{\mathrm{C}} \mathrm{H}-\mathrm{CHO} \mathrm{Na}+1 / 2 \mathrm{H}_{2}
$$

Ao tratar o produto da reação com água, ele não recuperava o aldeído, mas obtinha uma mistura orgânica complexa e hidróxido de sódio. Na mistura os produtos principais eram álcool amílico, ácido valérico, um composto de fórmula $\mathrm{C}_{10} \mathrm{H}_{22} \mathrm{O}$ e um outro formulado como $\mathrm{C}_{10} \mathrm{H}_{18} \mathrm{O}$. Este último devia ser um produto de condensação de duas moléculas de valeraldeído com a eliminação de uma molécula de água. Já a substância de fórmula $\mathrm{C}_{10} \mathrm{H}_{22} \mathrm{O}$ era um álcool primário, pois podia ser convertido em ésteres de acetato e benzoato, e oxidado a um ácido carboxílico. A fórmula molecular correspondia à condensação de duas moléculas de valeraldeído com a perda de um átomo de oxigênio. Borodin supôs que a substância fosse então um isômero do álcool correspondente ao ácido isocáprico. $\mathrm{O}$ ácido cáprico é o n-decanóico, e o isocáprico o 8-metilnanóico. O composto que Borodin chamava de ácido isocáprico era, na realidade, o ácido 2 propil-heptanóico, $\mathrm{CH}_{3}\left(\mathrm{CH}_{2}\right)_{4} \mathrm{CH}\left(\mathrm{C}_{3} \mathrm{H}_{7}\right) \mathrm{CH}_{2} \mathrm{OOH}$, e o produto de fórmula $\mathrm{C}_{10} \mathrm{H}_{22} \mathrm{O}$, que ele isolara, era o álcool correspondente a este ácido. A confusão de nomes não se deve a Borodin, e sim às variações sofridas com o tempo pela nomenclatura química.

Mais tarde, em 1869, ele passou a trabalhar com o enantaldeído, ou heptanal, que era preparado por destilação destrutiva do óleo de rícino. O comportamento do enantaldeído é semelhante ao do valeraldeído, com maior facilidade na eliminação de água.

Muito mais interessante, porém, foi o que ele descobriu ao diminuir o tamanho da cadeia do aldeído, usando o acetaldeído. A condensação deste composto forma uma nova substância contendo as funções aldeído e álcool:

\section{$2 \mathrm{CH}_{3} \mathrm{CHO} \rightarrow \mathrm{CH}_{3} \mathrm{CH}(\mathrm{OH}) \mathrm{CH}_{2} \mathrm{CHO}$}

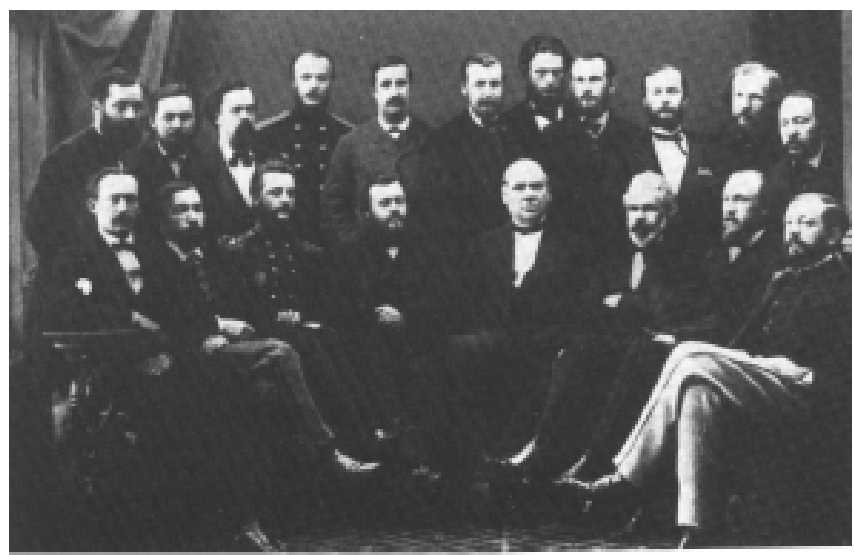

Figura 3. Reunião de químicos russos em São Petersburgo, 1868: o quarto e o quinto sentados, da esquerda para a direita, são, respectivamente, Vladimir Markovnikov e Alexandre Voskresenskii; em pé, na mesma ordem, Alexandre Borodin é o quinto, Friedrich Konrad Beilstein é o oitavo e Dmitri Mendeleev é o décimo
Por causa de sua bifuncionalidade, a nova substância foi chamada de aldol por Wurtz ${ }^{46}$, em trabalho posterior ao de Borodin. Todavia, a descoberta do aldol é geralmente creditada ao químico francês.

Borodin verificou também que o aldol, ao ser aquecido, elimina água e dá origem a um aldeído insaturado, o crotonaldeído:

\section{$\mathrm{CH}_{3} \mathrm{CH}(\mathrm{OH}) \mathrm{CH}_{2} \mathrm{CHO} \rightarrow \mathrm{CH}_{3} \mathrm{CH}=\mathrm{CHCHO}+\mathrm{H}_{2} \mathrm{O}$}

Estas reações estão na origem de uma extensa química de formação de polímeros, sobretudo de resinas, com as mais variadas aplicações. A condensação aldólica nunca ganhou o nome de condensação de Borodin, que foi seu primeiro descobridor. Ele comunicou seu trabalho à Sociedade Química Russa, que o publicou em sua revista em 1869 e $1872^{47}$. A revista alemã Berichte der Deutschen Chemischen Gesellschaft publicou também uma série de relatos sobre os trabalhos de Borodin neste assunto ${ }^{48}$, além de um artigo de sua autoria ${ }^{49}$.

Em 1858, Wurtz havia dado à luz um trabalho em que apenas mencionava que o acetaldeído se transformava em uma substância de alto ponto de ebulição por ação do cloreto de zinco ${ }^{50}$. Bauer, discípulo de Wurtz, mostrou que o novo composto, de ponto de ebulição $110^{\circ} \mathrm{C}$, podia ser oxidado pela prata amoniacal, o que condiz com o crotonaldeído ${ }^{51}$. No entanto, esse trabalho permaneceu inconcluso até a época das pesquisas de Borodin. Nessa altura, o químico alemão August Kekulé estava trabalhando ativamente na questão da estrutura do benzeno, cujo resultado veio a publicar em $1869^{52}$. Aparentemente ele desconhecia o artigo de 1864 de Borodin, mas deve ter visto o relato feito por von Richter em Berichte ${ }^{53}$. Kekulé estava interessado no assunto porque tinha a esperança de obter benzeno pela condensação de três moléculas de acetaldeído ${ }^{53}$. Por isso sentiu-se melindrado, reclamando do que considerava uma intrusão em seu território de pesquisa ${ }^{54}$, apesar dos trabalhos anteriores de Borodin e de Wurtz, os quais ele não cita. As críticas de Kekulé são também dirigidas ao químico francês Riban, que também havia começado a trabalhar no assunto e publicara uma comunicação inicial em $1870^{55}$. Ao contrário de Kekulé, Riban cita Borodin em seu artigo. Para aquilatar um pouco mais do espírito reinante, convém citar um trecho do artigo de Kekulés4:

"Acho lamentável que muitas pessoas considerem adequado apegar-se a investigações alheias que já começaram e são conhecidas por meio de comunicações preliminares, e continuá-las a partir daî." Mais adiante acrescenta que em virtude do que considerava uma intrusão em sua pesquisa, decidira cessar sua investigação sobre o assunto.

Borodin, todavia, continuou a trabalhar com os aldeídos e publicou vários artigos adicionais, como já se mencionou. $\mathrm{O}$ mesmo se deu com Riban ${ }^{56}$ e Wurtz que, em 1873, deu à luz um trabalho bem abrangente sobre o aldol ${ }^{46}$.

Após essa última publicação de Wurtz, Borodin decidiu encerrar seus trabalhos sobre o aldol, tendo justificado sua decisão em face às enormes dificuldades que enfrentava, comparando-as, com amargura, às condições do químico francês: "meu laboratório mal subsiste com os meios disponíveis. Não possuo sequer um assistente, ao passo que Wurtz tem recursos abundantes e trabalha com vinte subordinados, graças ao fato de que ele não se envergonha de sobrecarregar seus assistentes de laboratório com trabalho sujo" ${ }^{57}$.

Em uma carta particular de 1870, ele expressou um desabafo a respeito das acusações de Kekulé:

"Kekulé (em Bonn) me repreende como se eu me tivesse apropriado de seu trabalho (i.e., não o mesmo trabalho, de uma forma prática, mas a idéia do trabalho) com o valeraldeído (que estou execu- 
está explodindo, meus olhos lacrimejando, quando preciso tirar um lenço do bolso a cada dois minutos - aí eu escrevo música. Como é o caso agora, eu fiquei doente duas vezes durante o ano, e em ambas as ocasiões a enfermidade me permitiu botar novos tijolos no edifício de minha futura ópera" ${ }^{\prime 67}$.

No entanto, em 1870 ele chegou a desanimar da ópera, como chegou a confessar a Katia. Por isso, deixou Príncipe Igor de lado e voltou-se para sua Sinfonia Número 2, acabando a primeira parte em 1871. Ao final de 1874, contudo, o jovem médico V. A. Shanorov, ex-aluno de Borodin, chegou a São Petersburgo vindo do Cáucaso, e insistiu repetidamente com o professor para que terminasse a ópera. Borodin, porém, compunha em jorros, e não de forma contínua. No verão de 1875, estando em Moscou com a mulher, ele teve um período de grande criatividade e avançou bastante a ópera. Ao final de 1876 terminou a Sinfonia Número 2, que foi executada pela primeira vez em 2 de fevereiro de 1877 na Sociedade Russa de Música. É curioso notar que a Sinfonia Número 2 foi mal recebida pela alta roda de São Petersburgo, em virtude de seu caráter nacionalista e ultra-russo. No estrangeiro, contudo, fez grande sucesso, como o próprio Borodin pôde presenciar em pouco tempo.

Em julho de 1877 ele foi a Jena com seus estudantes Alexandre Pavlovich Dianin e Mikhail Yulevich Goldstein, os quais iam finalizar suas teses de doutorado na universidade daquela cidade alemã. Lá ele soube que Liszt vivia perto, em Weimar. Borodin foi visitar o reverenciado músico e descreveu a visita em carta a Katia:

"Eu nem havia conseguido apresentar meu cartão quando de repente, à frente de meu nariz, como se saída da terra, uma figura alta apareceu na entrada, num longo fraque negro, com um nariz comprido e longos cabelos grisalhos. 'Você compôs uma excelente sinfonia', bradou a figura em voz alta, e um braço longo se estendeu para mim. 'Bem-vindo, estou maravilhado... O primeiro movimento é excelente, seu andante é uma obra-prima, o scherzo delicioso, e esta passagem é tão engenhosa...' E assim por diante. Sua mão forte apertou firmemente a minha e ele me disse para sentar no sofá. Eu só conseguia assentir com a cabeça e agradecer-lhe. A figura majestosa do velho homem, com uma face enérgica, bela, animada, movia-se à minha frente e falava sem cessar, enchendo-me de perguntas sobre meus assuntos pessoais e sobre a música na Rússia, que evidentemente era muito bem conhecida dele. A conversa prosseguia ora em francês, ora em alemão, pulando continuamente de um para o outro. Quando eu disse a Liszt que sou, falando de forma rigorosa, um músico amador (na realidade um músico domingueiro), ele até fez um trocadilho: 'mas você sabe que domingo é sempre um feriado (Feiertag, em alemão), e você tem um direito absoluto de festejar (feiern)'. Ele ficou muitíssimo satisfeito com meus arranjos para piano e disse que eles revelam em mim um músico que é 'experimentado e extremamente talentoso, de posse de uma técnica contemporânea de piano"68.

Ao regressar à Rússia, Borodin retomou a rotina. Em 1879 terminou seu Primeiro Quarteto em sol maior e, durante o verão, trabalhou com afinco no libreto de Príncipe Igor. Um pesquisador francês, Jean-Albert Gautier, defende a tese de que a rivalidade de Kekulé causou um grande atraso e impediu a finalização de Príncipe Igor ${ }^{69}$. Como Borodin só trabalhava na ópera durante as férias de verão no campo, o progresso era realmente lento. Príncipe Igor permaneceu inacabada à época de sua morte, mas Rimsky-Korsakov e Alexandre Glazunov juntaram todas as partes num todo, e a ópera pode ser executada, obtendo êxito enorme.

Nos anos 80, sobretudo após o atentado que custou a vida ao Czar Alexandre II em 1881, o caráter opressivo do governo aumentou na Rússia. O governo decidiu que doravante não se devia tirar as pessoas do ambiente a que pertenciam, isto é, deveria deixar de existir a pouca mobilidade social que havia. Quem nascesse filho de criados, criado seria, e assim por diante. Em 1884 o Ministério da Educação baixou novas regras, restringindo severamente a autonomia das universidades. Os cursos para mulheres passaram a ser vistos como sediciosos: a partir de 1882 não mais se aceitaram novas matrículas, e em 1885 eles foram extintos ${ }^{70}$. Para Borodin o choque foi terrível, e ele trabalhou arduamente no pouco tempo de vida que lhe restava para tentar reverter o processo. Ao mesmo tempo o regime oprimia ainda mais as universidades, cortando-lhes as verbas e impedindo a contratação de novos servidores, num padrão de comportamento que não mudou até hoje em muitos regimes opressores no mundo. $\mathrm{O}$ ambiente se refletiu no trabalho de Borodin, que nos anos 80 não publicou nenhum artigo de pesquisa original. Ele continuou, porém, ativo como sempre, nas aulas, na música e em muitas atividades filantrópicas em que se via sempre envolvido. Sem filhos, ele e Katia adotaram três filhos. Também na orientação de estudantes sua participação continuou firme e constante.

Seu grande amigo Rimsky-Korsakov mais uma vez nos dá uma descrição de grande vivacidade e bom-humor da vida em família de Borodin:

"Seu apartamento era inconveniente, e parecia um corredor, nunca lhe permitindo isolar-se ou fingir que não estava em casa. Qualquer um entrava em sua casa a qualquer hora e o tirava do jantar ou do chá. O querido Borodin se levantava, com a comida ou a bebida pela metade, ouvia todo tipo de pedidos e queixas e prometia dar uma olhada. A isso se deve acrescentar que Ekaterina Sergeevna sofria constantemente de asma. Ela passava noites em claro e muitas vezes se levantava à meia-noite. Alexandre Porfirievich passava maus bocados com ela à noite, levantava-se cedo e não dormia o suficiente. Toda a sua vida doméstica era uma desordem sem fim. O horário de jantar e de outras refeições era completamente indefinido. Uma vez cheguei a sua casa às onze da noite e os encontrei a jantar. Deixando de lado as moças, suas protegidas, das quais nunca havia falta na casa, o apartamento era freqüentemente usado como abrigo ou local de pernoite por vários parentes pobres ou em visita, que escolhiam aquele lugar para caírem doentes ou enlouquecerem. Borodin se ocupava deles e os tratava, levava-os aos hospitais e muitas vezes ia lá visitá-los. Em quatro aposentos do apartamento, com freqüencia dormiam vários estranhos desse tipo; os sofás e o chão eram transformados em camas. Era impossível tocar piano porque alguém estava dormindo no cômodo vizinho. Também no jantar e no chá prevalecia uma grande desordem. Vários gatos que tinham feito seu lar no apartamento de Borodin gostavam de passear na mesa de jantar, enfiando os focinhos nos pratos e pulando sem qualquer cerimônia nas costas das pessoas. Esses gatos desfrutavam da proteção de Ekaterina Sergeevna...

Borodin era um homem sem afetações e fácil de se relacionar. Ele dormia pouco, mas conseguia dormir de qualquer jeito e em qualquer lugar. Podia jantar duas vezes no mesmo dia, ou não jantar nada, e ambas as situações aconteciam com freqüência"'.

Em 1881, ao completar 25 anos na Academia Médico-Cirúrgica, Borodin conquistou o direito de se aposentar. Ele dirigiu uma solicitação nesse sentido ao diretor da Academia, acrescentando um relatório pormenorizado de suas atividades ao longo daqueles $25 \operatorname{anos}^{71}$. Apesar disso, continuou trabalhando normalmente.

Na primavera de 1881 ele vai a Magdeburgo, na Alemanha, para o $18^{\circ}$ Congresso dos Músicos da Allgemeine Deutsche Musikverein (Sociedade Geral Alemã de Música). Depois segue até Weimar, para mostrar a Liszt seu novo poema sinfônico intitulado "Nas Estepes da Ásia Central", que ele havia dedicado ao músico húngaro. Ao retornar à Rússia escreveu a Alexandre Pavlovich Dianin (1851-1918), seu ex-aluno e futuro sucessor na cátedra: "Eu levei a cabo e concluí muito pouco a respeito de química no sentido de que, com nossa falta de recursos na Academia não se pode pensar na introdução de 
equipamentos, etc, que eu pudesse observar"72.

Durante os anos 80 Borodin escreveu várias peças musicais curtas, para piano, canções e música de câmara, como o Segundo Quarteto para Cordas. Em 1885 foi a Liège para participar de concertos de música russa, e pela terceira vez visitou Liszt em Weimar. Este tocou ao piano quatro peças do visitante. De Weimar, Borodin seguiu para Antuérpia, Paris e Liège. Tanto na Bélgica como na França foi festejado e ovacionado. Após seu retorno à Rússia, voltou a trabalhar em sua Sinfonia Número 3 no final de 1886. Ela permaneceu inacabada à época de sua morte, embora os dois primeiros movimentos, que ele chegou a acabar, sejam muito executados hoje em dia.

Na manhã de 15 de fevereiro de 1887, ou 27 de fevereiro no calendário gregoriano, ele compôs o final (quarto movimento) da Sinfonia Número 3, mas não o escreveu. À noite foi a um baile de carnaval a fantasia organizado por seus colegas da Academia. Às 23:40 h, durante o baile, Borodin de repente se encosta numa parede e sem um gemido cai morto no chão. A autópsia mostrou que ele havia sofrido um aneurisma cardíaco. Ademais a queda havia também provocado o choque de sua têmpora contra uma estufa, causando uma pequena hemorragia cerebral. Seu funeral foi apoteótico, com a presença de todas as mulheres médicas de São Petersburgo, em meio a toneladas de flores. Katia só lhe sobreviveu pouco tempo, vindo a falecer em 28 de junho do mesmo ano ${ }^{73}$. Borodin permanece enterrado no cemitério ao ar livre do Mosteiro Alexandre Nevsky, na principal avenida de São Petersburgo. A seu lado jazem alguns dos grandes expoentes da cultura russa do século 19: Mussorgsky, Tchaikovsky, Glinka, Balakirev, Rubinstein e Dostoievsky.

No segundo aniversário de sua morte, os amigos e admiradores de Borodin erigiram-lhe um monumento funerário de gosto discutível, que procura mostrar as várias facetas de sua vida polivalente. Além do busto de Borodin, o monumento ostenta esculturas representando instrumentos musicais tradicionais da Rússia e temas de obras do homenageado em mosaico sobre ouro, além das estruturas moleculares de vários dos compostos presentes em suas pesquisas químicas.

Enquanto o conhecimento a respeito da química de Borodin se esmaeceu com o tempo, sua obra musical tornou-se cada vez mais apreciada pela posteridade. Em 1953, os compositores americanos George Forrest e Robert Wright usaram e abusaram da música de Borodin ao criar seu popularíssimo musical da Broadway intitulado Kismet, de ambientação oriental. A partir daí ocorreu uma enorme difusão dos temas borodinianos, embora vulgarizados, ao ponto de transcrições populares desse musical, como a canção Stranger in Paradise, derivada das Danças Polovtsianas de Príncipe Igor, se terem tornado parte do repertório popular romântico dos Estados Unidos.

Contudo, é muito mais interessante considerar a figura de Borodin em sua inteireza, dados os aspectos tão peculiares de sua vida e carreira. Não só a música está aí para ser sorvida em sua rica forma original, de grande expressividade e força que se poderia denominar telúrica, mas também suas realizações na química são extraordinárias, sobretudo ao se considerar os fatores tão adversos contra os quais sempre teve que se bater.

É importante perceber que Borodin tinha uma característica peculiar, tanto em sua carreira científica como na musical. Observando a maneira como trabalhava, fica a impressão de que, após começar um novo trabalho original, ao cabo de algum tempo ele se desviava para outras coisas, como se já não se interessasse tanto por aquilo e buscasse continuamente algo novo. Isto fica claro, por exemplo, com relação à química do aldol. Não obstante seu pioneirismo, ele logo se desinteressou do assunto, que poderia ter sido mais explorado, mesmo com as críticas de Kekulé ou as condições difíceis de seu laboratório. Coube a Wurtz o trabalho de explorar até às últimas conseqüências aquela química. O papel de Borodin como químico fica assim, aparentemente, bastante diminuído a um observador menos atento. Na música era comum sua relutância em terminar o que começara, como se viu. A diferença desta para a ciência é que na música cada composição é única, e não haveria alguém para completar sua terceira sinfonia como se fora ele. Mesmo sendo a obra musical de Borodin não muito extensa, todavia, ela permanece no repertório universal, sendo executada regularmente em todo o mundo e contando legiões de admiradores.

\section{REFERÊNCIAS E NOTAS}

Os títulos dos artigos foram dados na íntegra, como se faz frequientemente em relatos dessa natureza, principalmente em se tratando de artigos antigos ou para facilitar o entendimento ou a busca para o leitor interessado. Os nomes dos periódicos antigos foram grafados por completo na primeira vez em que são citados, já que alguns desapareceram e outros mudaram de nome, até mais de uma vez, como se deu com Annalen.

1. Getman, F. H.; Alexander Borodin-Chemist and Musician; J. Chem. Educ. 1931, 8, 1763.

2. Wamser, C. A.; Wamser, C. C.; Lejaren A. Hiller, Jr. - A Memorial to a Chemist-Composer; J. Chem. Educ. 1996, 73, 601.

3. Sarton, G.; Borodin (1833-1887); Osiris 1939, 18, 521.

4. Friedman, H. B.; Alexander Borodin-Musician and Chemist; J. Chem. Educ. 1941, 18, 521.

5. Kauffman, G. B.; Rae, I. D; Solov'ev, I.; Steinberg, C.; Borodin, Composer and Chemist, Chem. Eng. News 1987, 65, 28.

6. White, A. D.; Alexander Borodin: Full-Time Chemist, Part-Time Musician; J. Chem. Educ. 1987, 64, 326.

7. Rae, I. D.; The Research in Organic Chemistry of Aleksander Borodin (1833-1887); Ambix 1989, 36, 121.

8. Figurovskii, N. A.; Solov'ev, Yu. I.; Aleksandr Porfir'evich Borodin-A Chemist's Biography, translated by Steinberg, C.; Kauffman, G. B.; Springer Verlag: Berlin Heidelberg, 1988.

9. Ref. 7 , p. 9

10. Ref. 7 , p. 10.

11. Ref. 7, p. 15 .

12. Ref. 7 , p. 18.

13. Ref. 7, p. 26

14. Borodin, A.; Ueber die Constitution des Hydrobenzamids und des Amarins; Justus Liebig's Annalen der Chemie und Pharmacie 1859, 110, 78

15. Borodin, A.; Ueber die Wirkung des Jodaethyls auf Benzoylanilid; Annalen 1859, 111, 254.

16. Hunter, D. H.; Kim, S. K.; J. Am. Chem. Soc. 1969, 91, 6202. Ibid.; Can. J. Chem. 1972, 50, 669. Ibid.; Can. J. Chem. 1972, 50, 678.

17. Berichte der Deutschen Chemischen Gesellschaft.; resumo; 1873, 6, 1253.

18. Borodin, A.; Ueber Nitrosoamarin; Berichte 1875, 8, 933.

19. Ref. 7, p. 26.

20. Filgueiras, C. A. L.; Quím. Nova na Escola, 1996, 22.

21. Borodin, A.; Ueber die Einwirkung des Jodäthyls auf Benzidin; Zeitschrift für Chemie und Pharmacie von E. Erlenmeyer und G. Lewinstein 1860, 3 , 533.

22. Shine, H. J.; Park, K. H.; Brownawell, M. L.; San Filippo, Jr., J.; J. Am. Chem. Soc. 1984, 106, 7077.

23. Zinin, N. N.; Ueber das Azobenzid und die Nitrobenzinsäure; Journal für Praktische Chemie 1845, 36, 93

24. Hofmann, A. W.; Ueber Azobenzol und Benzidin, Annalen 1860, 115, 362.

25. Fittig, R.; Ueber einige Derivate des Phenyls, Annalen 1862, 124, 275.

26. Ref. 7 , p. 31

27. Ref. 7, pp. $137-138$.

28. Ref. 7, p. 33.

29. É muito interessante ler o minucioso relato feito por Mendeleev a seu professor no Instituto Pedagógico de São Petersburgo, Alexandre Abramovich Voskresenskii (1809-1880), ref. 7, pp. 138-141.

30. Ref. 7, pp. 143-147.

31. Péligot, E. M.; Mémoire sur un acide résultant de l'action du brome sur le benzoate d'argent, Comptes Rendus de l'Académie des Sciences (Paris) 1836, 3,9 . 
32. Borodin, A.; Sur les dérivés monobromés des acides valérique et butyrique; Bulletin de la Société Chimique (Paris) 1861, 252.

33. Hunsdiecker, C.; Hunsdiecker, E.; Über den Abbau der Salze aliphatischen Säuren durch Brom; Berichte 1942, 75, 291.

34. Jacques, J.; À propos de la réaction de Borodine-Hunsdiecker; Comptes Rendus 1999, t. 2, série IIc, 181.

35. Borodin, A.; Beitrag zur Geschichte des Benzyls; Zeit. Chem. Pharm. 1861, 4,8 .

36. Ref. 7, p. 42.

37. Dumas, J. B. A.; Péligot, E. M.; Annales de Chimie et Physique 1836, 61, 193. Citado na ref. 7, p. 46

38. Frémy, E.; Annales Chim. Phys. 1856, 46, 1748; 1856, 47, 5. Citados na ref. 7, p. 46.

39. Borodin, A.; Faits pour servir à l'histoire des fluorures et préparation du fluorure de benzoyle; Comptes Rendus 1862, 55, 553.

40. Ref. 7, p. 42.

41. Ref. 7, pp. $49-50$

42. Ref. 7, pp. 50-51.

43. Ref. 7 , p. 51

44. Ref. 7, p. 58

45. Borodin, A.; Über die Einwirkung des Natriums auf Valeraldehyd; J. Prakt. Chem. 1864, 93, 413.

46. Wurtz, A.; Nouvelles recherches sur l'aldol; Comptes Rendus 1873, 76, 1165

47. Ref. 7, p. 75 .

48. Berichte; resumos; $\mathbf{1 8 6 9}, 2$, 552; 1870, 3, 423; 1872, 5, 480, 1873, 6, 1253.

49. Borodin, A.; Ueber einen neuen Abkömmling des Valerals; Berichte 1873, 6,982

50. Wurtz, A.; Sur les éthers du glycol; Comptes Rendus 1858, 47, 34.
51. Bauer, A; Ueber einen neuen mit dem Aldehyd isomerin Körper; Annalen 1860, 117, 141 .

52. Kekulé, A.; Ueber die Constitution des Benzols; Berichte 1869, 2, 362.

53. Berichte; resumos; 1869, 2, 552.

54. Kekulé, A; Ueber die Condensation der Aldehyde; Berichte 1870, 3, 135.

55. Riban, M. J.; Sur les produits de condensation de l'aldéhyde valérique; Bull. Soc. Chim. 1870, 13, 24.

56. Riban, M. J.; Sur les aldéhydes condensés avec élimination d'eau ou aldanes; Comptes Rendus 1872, 75, 96.

57. Ref. 7, p. 65.

58. Aqui há um engano evidente de Borodin, pois seu primeiro artigo publicado sobre o assunto data de 1864 .

59. Ref. 7, p. 66.

60. Berichte; resumos; 1876, 9, 1029; 1877, 10, 1105.

61. Ref. 7, p. 72

62. Ref. 7 , p. 80

63. Ref. 7, pp. 82-84.

64. Ref. 7, p. 148.

65. Ref. 7, p. 89.

66. Ref. 7, p. $90,152$.

67. Ref. 7 , p. 96.

68. Ref. 7, p. 100.

69. Gautier, J.-A.; Comment les découvertes du chimiste Kekulé empêchèrent Borodine de terminer le Prince Igor; Rev. Hist. Pharm. 1970, 20, 5.

70. Ref. 7, p. 109.

71. Ref. 7, pp. 151-152.

72. Ref. 7, p. 113

73. Ref. 7, pp. 114- 115 